\title{
Liquid Phase Photooxidation of Toluene in the Presence of Transition Metal Oxide Doped Titania
}

\author{
S. Riyas, ${ }^{a}$ G. Krishnan ${ }^{b}$ and P. N. Mohan Das ${ }^{*, a}$ \\ ${ }^{a}$ Regional Research Laboratory (CSIR), Trivandrum- 695 019, India \\ ${ }^{b}$ Reader and Head, Department of Chemistry, University College, Trivandrum, India
}

\begin{abstract}
O tolueno é um composto orgânico muito tóxico utilizado para a preparação de muitos outros compostos. A fotoxidação do tolueno em fase líquida foi realizada utilizando-se amostras policristalinas do $\mathrm{TiO}_{2}$ dopado com óxidos de metais de transição, contendo diferentes fases de dióxido de titânio conhecidas como anatase, rutilo e a mistura de anatase e rutilo. O objetivo principal desse estudo foi investigar a conversão de tolueno a ácido benzóico e como cada fase modificada do $\mathrm{TiO}_{2}$ afeta a velocidade da reação. As diferentes fases foram caracterizadas com base em difração de Raios X. Outros métodos, tais como, análises químicas, medidas de área de superfícies e cálculo do tamanho do cristal também foram utilizados para a caracterização das amostras. A fase da anatase dopada com metais de transição gerou maior rendimento do que a do rutilo dopado. A mistura de anatase e rutilo não apresentou efeito significativo.
\end{abstract}

Toluene is a very noxious organic compound used for the preparation of many compounds. Liquid phase photo-oxidation of toluene was carried out using poly crystalline samples of transition metal oxide doped $\mathrm{TiO}_{2}$ containing different phases of titania, namely anatase, rutile and mixture of anatase and rutile. The main objective was to find out the conversion of toluene to benzoic acid and how the phase modification of doped $\mathrm{TiO}_{2}$ affects the reaction rate. The different phases of $\mathrm{TiO}_{2}$ were determined using powder X-ray diffraction. Other methods such as chemical analysis, Surface area measurements and Crystallite size calculation were also used for the characterization of the samples. Anatase doped with transition metal oxides gives higher yield than doped rutile. Mixture of anatase and rutile has no significant effect.

Keywords: toluene, doped $\mathrm{TiO}_{2}$, photo-oxidation, transition metal oxides, benzoic acid, titania

\section{Introduction}

Benzoic acid has many industrial applications. The first change in benzoic acid preparation came in 1850s when hippuric acid $\left(\mathrm{C}_{6} \mathrm{H}_{5} \mathrm{CONHCH} \mathrm{H}_{2} \mathrm{COOH}\right)$, from the urine of horses and cattle, replaced gum benzoin as the starting material. Hippuric acid was used extensively until 1870, when coal tar raw materials were utilized for the first time. ${ }^{1,2}$ Phthalic acid was also used as the raw material until 1890, when the hydrolysis of benzotrichloride took over the bulk production. This route and the one employing chlorination of toluene to benzyl chloride and subsequent oxidation with $\mathrm{HNO}_{3}$ to benzoic acid remained as the major production route until after World War I. After World War II, another change started in manufacturing technique of benzoic acid, as the air

*e-mail: daspnm@rediffmail.com oxidation of toluene was started in Germany and after the war, this method was carried over to the US. The air oxidation in liquid phase using cobalt catalysts has now become the main manufacturing method in the US. Considering the present and future petrochemical economic factors, it is difficult to foresee any commercial raw material other than toluene for benzoic acid production. ${ }^{1,2}$ Benzoic acid has many industrial applications such as, in medicines, veterinary medicines, food and industrial preservatives, dye stuffs, synthetic fiber. ${ }^{1}$

Most metal oxides, when used in the technical applications are functionalized through doping or used in combination with other oxides. Titania is to date the most suitable photocatalyst semi conducting material due to its high stability towards photocorrosion and its relatively favorable bandgap energy. Doping can have a variety of consequences as it may alter the structure, electronic properties and thermal stability. There is now sufficient information on pure $\mathrm{TiO}_{2}$ 
that one can confidently introduce in a well controlled way impurities and dopants. Surface investigations on doped $\mathrm{TiO}_{2}$ show that the local variations of electronic structure. ${ }^{3}$ Doping $\mathrm{TiO}_{2}$ with transition metal oxides increases the quantum yield in photocatalytic degradation process and $\mathrm{TiO}_{2}$ in gas sensors is usually doped with noble metals. Dopant increases the photocatalytic activity of $\mathrm{TiO}_{2}$ films. The mechanism can be attributed to as the anatase grain sizes decrease with doping and the specific surface areas of doped $\mathrm{TiO}_{2}$ films increase, the charge transfer in $\mathrm{TiO}_{2}$ film is promoted also by enhancing the electron-hole pair separation and inhibiting their recombination, the dopant enhances the charge pair separation efficiency for doped $\mathrm{TiO}_{2}$ films. ${ }^{3}$ Heterogeneous photocatalysis in the presence of semi conductor oxides is a fast growing field of basic and applied research, especially for the oxidation of organic pollutants in water.-6

Ibusuki and Takeuchi ${ }^{7}$ carried out the complete photooxidation of toluene on $\mathrm{TiO}_{2}$ at room temperature. They found that the presence of water vapour was beneficial in order to achieve the almost complete mineralization of toluene, benzaldehyde having been detected only in very small amounts. However, the product distribution and catalyst stability strongly depend on the nature of the catalyst and the experimental conditions. Furthermore, Obee and Brown ${ }^{8}$ studied the influence of the competitive adsorption of water and toluene vapours on the photooxidation rate. Luo and Ollis ${ }^{9}$ and Einaga et al. ${ }^{10}$ by studying the toluene degradation in humidified air, report that the influence of water is complex in the sense that an optimum water concentration was found for which maximum reactivity was observed. In any case no significant amounts of intermediate species were detected. Recently the selective photooxidation of gaseous toluene to benzaldehyde on $\mathrm{TiO}_{2}$ powder has been reported as an effective method to transform this compound to a valuable chemical. ${ }^{11,12}$ Moreover, Cao and co-workers ${ }^{13}$ reported the photo catalytic oxidation of toluene by using nano structured $\mathrm{TiO}_{2}$ catalysts. They found a sever deactivation of $\mathrm{TiO}_{2}$ due to the accumulation of partially oxidized intermediates. The complete recovery of catalytic activity required a thermal treatment of the photocatalysts at a temperature above $420{ }^{\circ} \mathrm{C}$.

Fujihira et al. ${ }^{14,15}$ studied the photooxidation of toluene in aqueous aerated suspensions containing various powdered semiconductors. They reported the formation of cresols, benzaldehyde and benzyl alcohol, depending on the $\mathrm{pH}$ of the solution and on the used semiconductor. The formation of benzaldehyde was also confirmed by Navio et al.,${ }^{16}$ which used acetonitrile as solvent and investigated the influence of the presence of water on the product distribution. Recently the use of a surfactant to enhance the photocatalytic reaction rate for toluene degradation has been reported. ${ }^{17} \mathrm{TiO}_{2}$ is the most used and popular photocatalyst for various reasons, but unfortunately, although a large shift of light absorption in the visible region has been observed in almost all cases, the presence of dopant metal species has not been reported beneficial when photooxidation reactions of organic substrates in aqueous systems were carried out. ${ }^{18-21}$ Numerous investigations are in progress for the improvement of the catalytic activity of $\mathrm{TiO}_{2}$. $\mathrm{TiO}_{2}$ can crystallize in different structures, rutile being the stable one. The anatase to rutile transformation does not have a transition temperature because there is no phase equilibria involved. ${ }^{22}$ Anatase transforms irreversibly and exothermally to rutile in the range $880-1200 \mathrm{~K}^{23,24}$

Some authors have reported that the recombination rate of the electron-hole pairs increases for chromium doped $\mathrm{TiO}_{2}$ with respect to undoped $\mathrm{TiO}_{2}$. The photocatalytic oxidation of acetic acid over $\mathrm{TiO}_{2}$ was markedly enhanced by dissolved copper ions. ${ }^{25}$ Several authors have studied the $\mathrm{TiO}_{2}$ photocatalytic oxidation of benzene and toluene in air or oxygen. Formation of $\mathrm{CO}_{2}$ was reported in all these studies. ${ }^{26-38}$ Analysis of the products showed the formation of benzyl alcohol, benzaldehyde ${ }^{27}$ and also benzoic acid ${ }^{28,29}$ in the case of toluene oxidation. Similarly it was reported that the photocatalytic decomposition of toluene in aqueous $\mathrm{TiO}_{2}$ suspension was significantly promoted in the presence of copper, ferrous and manganese ions. ${ }^{39}$ However there is no promoting effect on the photocatalytic decomposition of phenol in the presence of silver ion. ${ }^{40,41}$ Moreover many other dopants are available on metal doped $\mathrm{TiO}_{2}$ preparations to efficiently decompose toxic compounds.

The objective of this work is to study of influence of different phase compositions of $\mathrm{TiO}_{2}$ on the liquid phase photooxidation of toluene using different transition metal oxides of $\mathrm{Fe}, \mathrm{Cr}, \mathrm{Ni}, \mathrm{Cu}$ and $\mathrm{Mn}$-doped $\mathrm{TiO}_{2}$. During the heat treatment, these metal oxides diffuse to the $\mathrm{TiO}_{2}$ lattice to form doped $\mathrm{TiO}_{2}$. Irradiations were done for different hours and the samples collected after particular duration was analyzed for the benzoic acid content. The reaction was carried out after calcination of the samples at different temperatures and time for obtaining different phase compositions of $\mathrm{TiO}_{2}$. The samples so prepared were subjected to powder XRD, in order to investigate the phase transformation in presence of above transition metal oxides. The results obtained are summarized in this paper.

\section{Experimental}

\section{Chemicals used for sample preparation}

$\mathrm{TiO}_{2}$ pulp (uncalcined pure hydrated $\mathrm{TiO}_{2}$ containing $75 \%$ amorphous $\mathrm{TiO}_{2}$ ) obtained from a $\mathrm{TiO}_{2}$ manufacturing 
factory, Travancore Titanium Products Ltd. Trivandrum, India, ferric nitrate (s.d.fine-chem Ltd), chromium trioxide (s.d.fine-chem. Ltd), nickel nitrate (MERCK), copper nitrate (A.R. s.d.fine-chem. Ltd.), manganous sulfate (A.R. s.d.fine-chem. Ltd.), hydrazine hydrate (L.R, s.d. fine-chem Ltd), sulfuric acid (98\%, s.d. fine-chem), ammonium sulphate (L.R, s.d.fine-chem), toluene (99\% -Ranbaxy)

\section{Sample preparation}

$\mathrm{TiO}_{2}$ doped with different transition metal oxides were prepared as follows: $15 \%$ transition metal oxide doped $\mathrm{TiO}_{2}$ was prepared by taking $35.29 \mathrm{~g} \mathrm{TiO}$, pulp, $660 \mathrm{~g}$ $\left(\mathrm{NH}_{4}\right)_{2} \mathrm{SO}_{4}, 825 \mathrm{~mL}$ conc: $\mathrm{H}_{2} \mathrm{SO}_{4}$. The mixture was heated until a clear solution was obtained. It was then cooled and diluted to about $1 \mathrm{~L}$. Transition metal salt dissolved in distilled water was added to the clear solution and mixed well. Titanium and metal ions were then precipitated together by the addition of hydrazine hydrate until the $\mathrm{pH}$ was $c a$. 9. The precipitate so obtained was washed with distilled water till it was free from sulphate ions. Then filtered with Whatman No. 42 filter paper and dried in an oven at $110^{\circ} \mathrm{C}$ for $3 \mathrm{~h}$ and calcined in a muffle furnace at different temperatures for $5 \mathrm{~h}$ for converting anatase to rutile and to get doped $\mathrm{TiO}_{2}$. According to the nature of transition metal oxide present anatase to rutile transformation temperatures are different. $23,24,42,43$

\section{Characterization of the samples}

The calcined samples were subjected to chemical analysis using standard procedures. Titanium was estimated by Aluminium reduction method,${ }^{44}$ iron by titration against $0.01 \mathrm{~mol} \mathrm{~L}^{-1} \mathrm{~K}_{2} \mathrm{Cr}_{2} \mathrm{O}_{7}$ and chromium and manganese by titration against standard $\mathrm{KMnO}_{4}$ solution. ${ }^{45}$ Nickel and copper were estimated gravimetrically using dimethyl glyoxime and thiocyanate respectively. ${ }^{44}$ XRD studies were carried out by the powder diffraction technique. The percentage of rutile formed was calculated from XRD patterns using the equation

$\%$ Rutile $=1 \times 100 / 1+0.794 \mathrm{I}_{\mathrm{A}} / \mathrm{I}_{\mathrm{R}}$

where $I_{A}$ and $I_{R}$ are the peak intensities of [101] and [110] planes for anatase and rutile respectively. The ' $d$ ' values were compared with standard ASTM values. Philips automatic powder X-ray diffractometer (PW 1710 with $\mathrm{CuK}_{\alpha}$ wavelength) was used for XRD studies. ${ }^{41}$ Ordinary muffle furnace with a temperature programmer was used for calcination purpose. Surface area measurements were done using a Gemini 2360 V4.01 Surface area analyzer (Micro Meritics Instrument Corporation, USA). These were done by BET method of nitrogen adsorption at liquid nitrogen temperature using Gemini 2360 V4.01 instrument by taking accurately $0.5 \mathrm{~g}$ of the sample. ${ }^{46}$

\section{Photocatalytic oxidation of toluene}

Figure1 represents the geometry of catalytic reactor used, which was made of pyrex glass and had $25 \mathrm{~cm}$ height and $30 \mathrm{~mm}$ and $18 \mathrm{~mm}$ outer and inner diameters respectively. It was fitted with annular water cooling jackets fabricated from glass not transmitting light of wave length $<300 \mathrm{~nm}$. The toluene oxidation activity studies were carried out using Fe-doped $\mathrm{TiO}_{2}$, Ni-doped $\mathrm{TiO}_{2}, \mathrm{Cr}$-doped $\mathrm{TiO}_{2}$, Mn-doped $\mathrm{TiO}_{2}$, and $\mathrm{Cu}$-doped $\mathrm{TiO}_{2}$ samples with different phase compositions of $\mathrm{TiO}_{2}$ as per the following procedure.

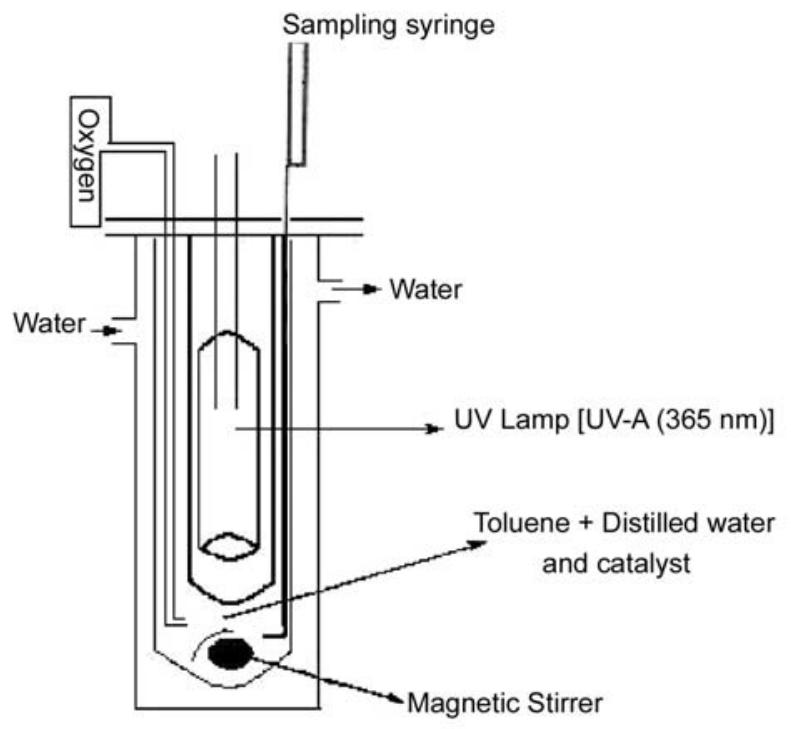

Figure 1. Schematic representation of the photocatalytic reactor used for liquid phase toluene oxidation in presence of transition metal oxide doped $\mathrm{TiO}_{2}$.

$0.250 \mathrm{~g}$ metal oxide doped $\mathrm{TiO}_{2}$ sample (with different phase content) was taken in photoreactor and $247.3 \mathrm{~mL}$ distilled water was added. It was then kept on a magnetic stirrer and oxygen was bubbled continuously. $2.7 \mathrm{~mL}$ of toluene was then added and the photooxidations were done by using UV-A (365 nm) irradiation for different durations. After each hour, sample was taken and analyzed for benzoic acid formation. The benzoic acid formed was estimated by titrating against standard $0.1 \mathrm{~mol} \mathrm{~L}^{-1} \mathrm{NaOH}$ solution using phenolphthalein as indicator. The proposed reaction is $\mathrm{C}_{7} \mathrm{H}_{8}+3 / 2 \mathrm{O}_{2} \rightarrow \mathrm{C}_{7} \mathrm{H}_{6} \mathrm{O}_{2}+\mathrm{H}_{2} \mathrm{O}$. 
Table 1. Chemical and phase compositions of transition metal oxide doped $\mathrm{TiO}_{2}$ heated at different temperatures for $5 \mathrm{~h}$ used for photooxidation

\begin{tabular}{lcccc}
\hline Sample & Metal Oxide/ $(\%)$ & $\mathrm{TiO}_{2} /(\%)$ & $\begin{array}{c}\text { Calcination } \\
\text { Temperature/ }\left({ }^{\circ} \mathrm{C}\right)\end{array}$ & Phase Composition \\
\cline { 3 - 5 } $\mathrm{Fe}_{2} \mathrm{O}_{3}$ doped $\mathrm{TiO}_{2}$ & 14.39 & 84.4 & 800 & 47 \\
$\mathrm{Cr}_{2} \mathrm{O}_{3}$ doped $\mathrm{TiO}_{2}$ & 14.89 & 84.9 & 700 & 53 \\
$\mathrm{NiO}$ doped $\mathrm{TiO}_{2}$ & 14.72 & 84.89 & 800 & 72 \\
$\mathrm{CuO}$ doped $\mathrm{TiO}_{2}$ & 14.92 & 84.88 & 750 & 54 \\
$\mathrm{MnO}_{2}$ doped $\mathrm{TiO}_{2}$ & 14.87 & 84.93 & 700 & 50 \\
\hline
\end{tabular}

\section{Results and Discussion}

\section{Material characterization}

To establish the amount of dopants, chemical analysis of transition metal oxide doped $\mathrm{TiO}_{2}$ samples were performed. The chemical and phase compositions of doped samples are given in Table 1.

Figure 2 represents the XRD patterns of calcined samples of transition metal oxide doped $\mathrm{TiO}_{2}$ heated at different temperatures for $5 \mathrm{~h}$. It is found that on heating anatase-rutile transformation in $\mathrm{TiO}_{2}$ takes place. The peak at $2 \theta=25.30^{\circ}$ corresponds to anatase and the peak $27.48^{\circ}$ is that of rutile phases of $\mathrm{TiO}_{2}$. The extent of rutilation

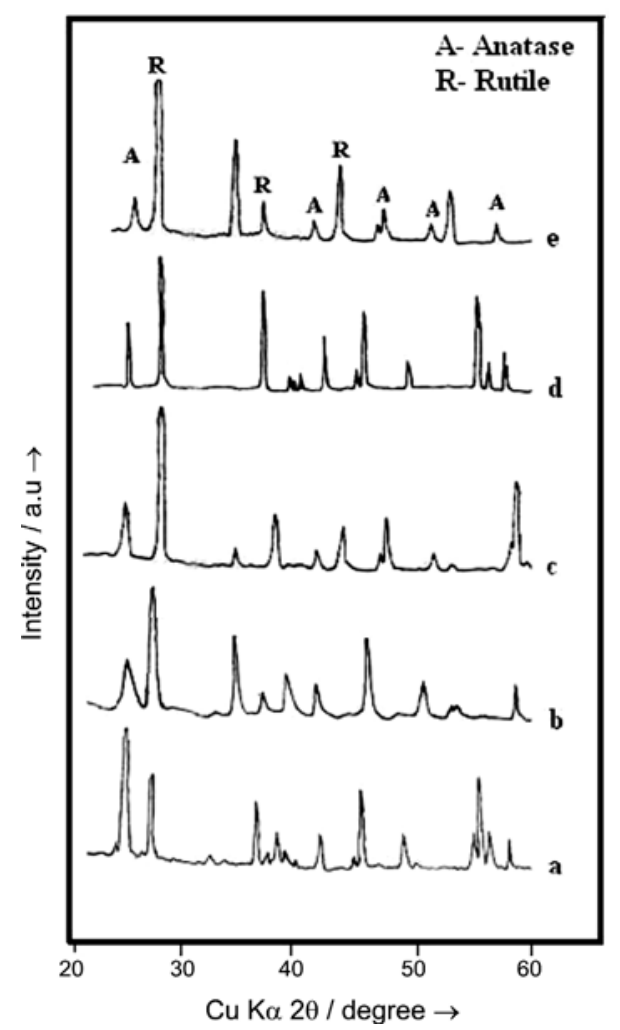

Figure 2. XRD patterns transition metal oxide doped $\mathrm{TiO}_{2}$ heated at different temperatures for $5 \mathrm{~h}$. (a) $\mathrm{Fe}_{2} \mathrm{O}_{3} / \mathrm{TiO}_{2}$ heated at $800^{\circ} \mathrm{C}$. (b) $\mathrm{Cr}_{2} \mathrm{O}_{3} /$ $\mathrm{TiO}_{2}$ heated at $700^{\circ} \mathrm{C}$. (c) $\mathrm{NiO} / \mathrm{TiO}_{2}$ heated at $800^{\circ} \mathrm{C}$. (d) $\mathrm{CuO} / \mathrm{TiO}_{2}$ heated at $750{ }^{\circ} \mathrm{C}$. (e) $\mathrm{MnO}_{2} / \mathrm{TiO}_{2}$ heated at $700{ }^{\circ} \mathrm{C}$. depends on the nature of transition metal oxide present. Since there is no peak corresponding to metal oxide in any XRD pattern, formation of doped $\mathrm{TiO}_{2}$ can be confirmed. Surface area of all the samples decreased drastically up on rutilation and the crystallite size of doped titania samples increased with rutilation (Table 2). The lowering of surface area depends on the nature of metal oxide doped since the diffusion of dopant to the oxygen vacancy concentration in the $\mathrm{TiO}_{2}$ lattice during rutilation temperature different for different ions, which breaks the Ti-O bond in anatase lattice and rearranges to the rutile structure. The decrease in surface area could also originate from a coalescence process since sintering is favored by the presence of dopants. ${ }^{47,48}$

Table 2. Surface area and crystallite size of transition metal oxide doped $\mathrm{TiO}_{2}$ used for photooxidation

\begin{tabular}{lccc}
\hline \multirow{2}{*}{ Sample } & \multicolumn{2}{c}{ Surface area $/\left(\mathrm{m}^{2} \mathrm{~g}^{-1}\right)$} & Crystallite size / $(\mathrm{nm})$ \\
\cline { 2 - 3 } & $\begin{array}{c}\text { Before } \\
\text { rutilation }\end{array}$ & $\begin{array}{c}\text { After } \\
\text { rutilation }\end{array}$ & $\begin{array}{c}\text { After rutilation) } \\
\mathrm{Fe}_{2} \mathrm{O}_{3} / \mathrm{TiO}_{2}\end{array}$ \\
$\mathrm{Cr}_{2} \mathrm{O}_{3} / \mathrm{TiO}_{2}$ & 109.5 & 4.3 & 18.8 \\
$\mathrm{NiO}_{\mathrm{TiO}}$ & 178.6 & 9.1 & 7.3 \\
$\mathrm{CuO} / \mathrm{TiO}_{2}$ & 192.7 & 1.9 & 31.6 \\
$\mathrm{MnO}_{2} / \mathrm{TiO}_{2}$ & 132.2 & 6.1 & 14.3 \\
\hline
\end{tabular}

The anatase to rutile transformation is accompanied by a crystallographic re- arrangement in $\mathrm{TiO}_{2}$ lattice. How this phase transformation affects the photooxidation using the above catalysts is discussed in the following section.

\section{Photooxidation of toluene using doped titania}

With undoped $\mathrm{TiO}_{2}$

To compare and ascertain the role of transition metal oxides, experiments were carried out using undoped anatase phase $\mathrm{TiO}_{2}$. Figure 3 represents benzoic acid formed during irradiation and it was observed that the benzoic acid formation increases with irradiation time. Sample collected after irradiation for $6 \mathrm{~h}$ contained $7.3 \%$ benzoic acid and for $12 \mathrm{~h}$ it was $28.7 \%$. 


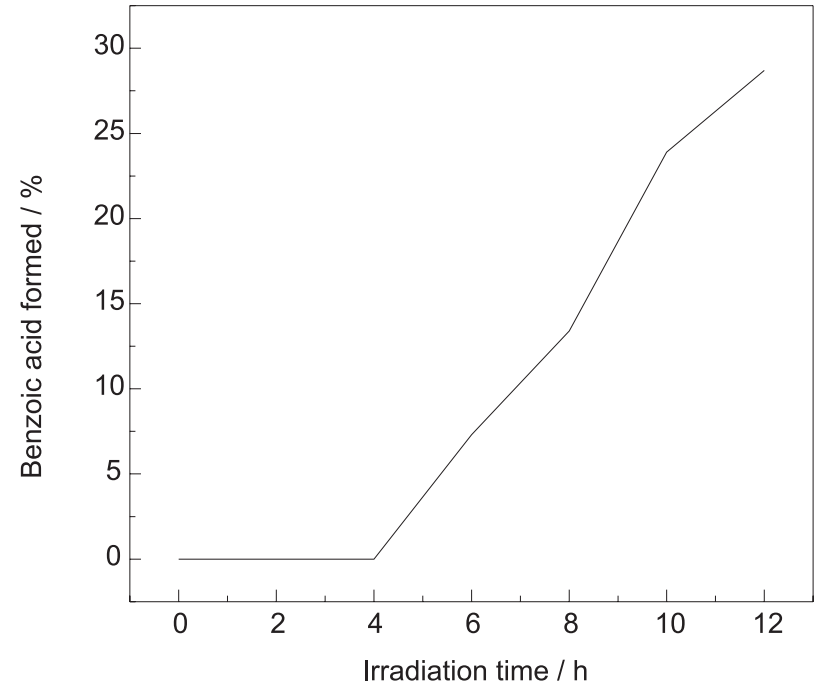

Figure 3. Variation in benzoic acid formation with irradiation time in undoped $\mathrm{TiO}_{2}$.

\section{With Fe-doped $\mathrm{TiO}_{2}$}

Figure 4 represents the variation in toluene oxidation activity of $15 \%$ Fe-doped $\mathrm{TiO}_{2}$ It is found that toluene oxidation is considerably affected by the phase transformation in $\mathrm{TiO}_{2}$. The conversion obtained with $\mathrm{Fe}_{2} \mathrm{O}_{3}$ on anatase $\mathrm{TiO}_{2}$ was $92.4 \%$ for $10 \mathrm{~h}$ irradiation. But the conversion obtained was $36.4 \%$ when anatase phase was replaced with rutile. The oxidation was found to be lowered by the phase transformation in $\mathrm{TiO}_{2}$ support. Rutilation reduced the oxidation process and also percentage conversion was low (28.6\%) with Fe-doped $\mathrm{TiO}_{2}$

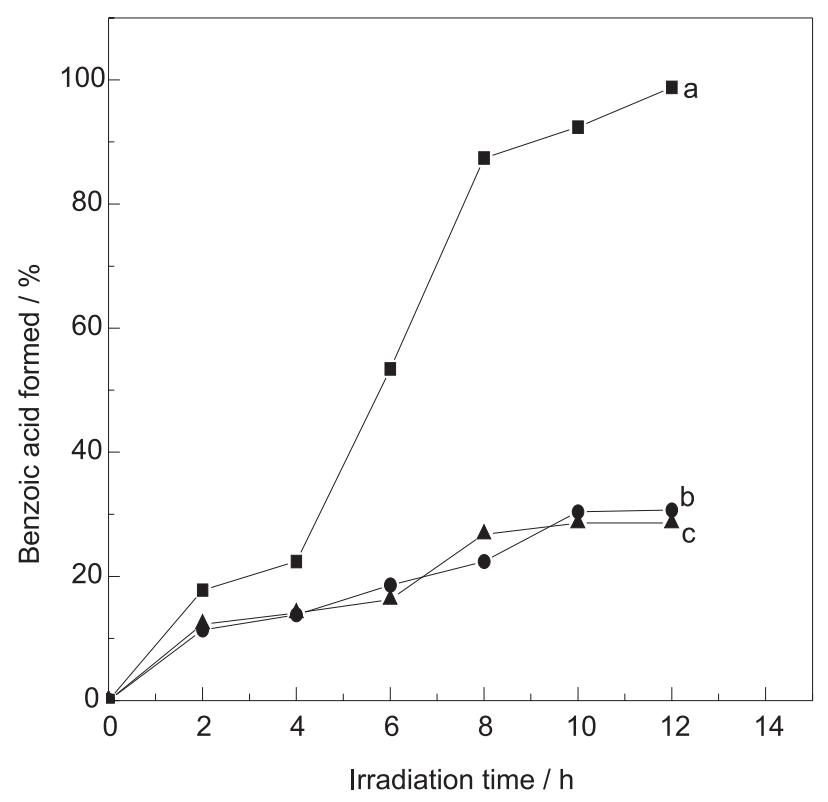

Figure 4. Variation in benzoic acid formation with phase composition of $15 \% \mathrm{Fe}_{2} \mathrm{O}_{3}$ doped $\mathrm{TiO}_{2}$ systems. a. Containing anatase; b. Containing rutile; c.Containing both anatase and rutile. containing both anatase and rutile phases as compared to one containing anatase phase alone.

The lowering of activity can be ascribed to the decrease in surface area of these samples during the phase transformation. Anatase has got better activity, as expected, due to its enhanced properties compared to rutile. The presence of rutile along with anatase also reduces the catalytic activity of Fe-doped $\mathrm{TiO}_{2}$.

As compared to undoped $\mathrm{TiO}_{2}$, the toluene oxidation activity is increased on doping oxide of $\mathrm{Fe} .12 \mathrm{~h}$ irradiation produced $98.8 \%$ benzoic acid in presence of $\mathrm{Fe}$ - doped $\mathrm{TiO}_{2}$ while in presence of undoped $\mathrm{TiO}_{2}$ only $28.7 \%$ benzoic acid was formed at the same conditions. Hence it is clear that Fe-doping has some enhancing effect on photooxidation of toluene and hence Fe-doped $\mathrm{TiO}_{2}$ can be used as a better catalyst for the reaction than pure $\mathrm{TiO}_{2}$. Decrease in the catalytic activity of the system with rutilation may also be due to the changes in distribution of metal oxide on the surface of $\mathrm{TiO}_{2}$ with the crystal transformation as well as metal titanate formation at higher temperature where rutilation occurs. So, the reaction is influenced by the phase changes occurring in the support material.

\section{With Cr-doped $\mathrm{TiO}_{2}$}

Benzoic acid formation using $15 \% \mathrm{Cr}$-doped $\mathrm{TiO}_{2}$ with anatase, rutile and mixture of anatase and rutile phases is given in Figure 5. The photooxidation activity of Cr-doped $\mathrm{TiO}_{2}$ is affected by the rutilation in $\mathrm{TiO}_{2}$. The conversion obtained with $\mathrm{Cr}$ - doped with anatase $\mathrm{TiO}_{2}$ was $100 \%$ for $10 \mathrm{~h}$ irradiation. But the conversion obtained was $33.3 \%$ when anatase phase was replaced with rutile. Benzoic acid formation was $30.8 \%$ with $\mathrm{Cr}_{2} \mathrm{O}_{3} / \mathrm{TiO}_{2}$ containing

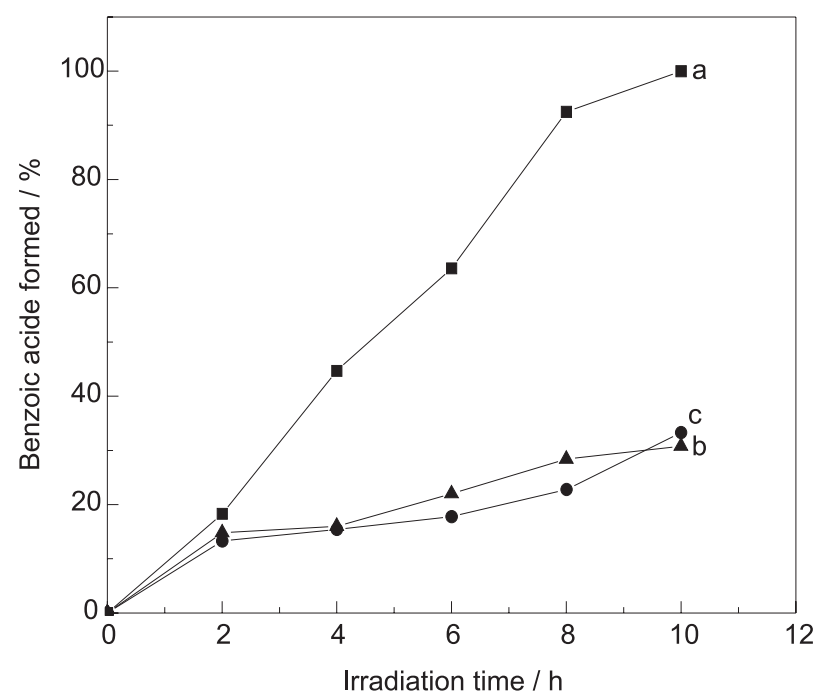

Figure 5. Variation in benzoic acid formation with phase composition of $15 \% \mathrm{Cr}_{2} \mathrm{O}_{3}$ doped $\mathrm{TiO}_{2}$ systems. a. Containing anatase; b. Containing rutile; c. Containing both anatase and rutile. 
both anatase and rutile phases. Thus change in the phase composition of $\mathrm{TiO}_{2}$ affects the photooxidation of toluene using Cr-doped $\mathrm{TiO}_{2}$.

Cr-doped $\mathrm{TiO}_{2}$ is also a good catalyst for the reaction compared to undoped $\mathrm{TiO}_{2}$ since $10 \mathrm{~h}$ irradiation produced $100 \%$ conversion of toluene to benzoic acid and this system is better than $\mathrm{Fe}$-doped $\mathrm{TiO}_{2}$. Anatase is the best as expected, due to its better properties compared to rutile. Also there is a drastic decrease in surface area at the completion of rutilation. This reaction is also influenced by the phase changes in the support material on which oxide of Chromium is present.

\section{With $\mathrm{Ni}$-doped $\mathrm{TiO}_{2}$}

Figure 6 represents the different percentages of benzoic acid formed during irradiation of aqueous suspension of toluene containing Ni-doped $\mathrm{TiO}_{2}$ with different phases. It is found that the conversion to benzoic acid is very low as compared to other catalyst systems under investigation. On irradiation for $8 \mathrm{~h}$ with $\mathrm{Ni}$-doped on anatase $\mathrm{TiO}_{2}$, only $6.5 \%$ benzoic acid was formed.

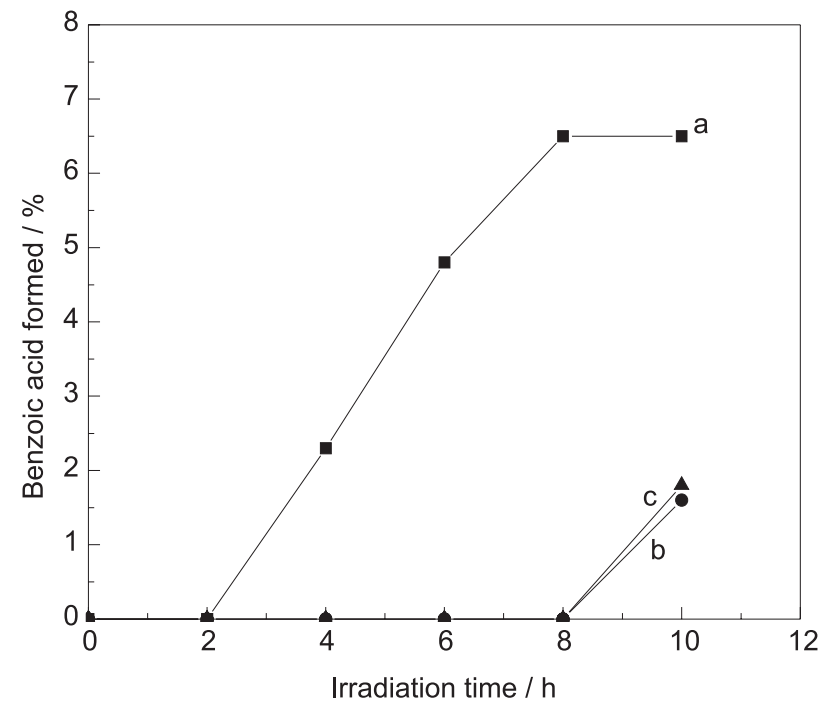

Figure 6. Variation in benzoic acid formation with phase composition of $15 \% \mathrm{NiO}$ doped $\mathrm{TiO}_{2}$ systems. a. Containing anatase; b. Containing rutile; c. Containing both anatase and rutile.

$\mathrm{Ni}$-doped on rutile $\mathrm{TiO}_{2}$ for $8 \mathrm{~h}$ irradiation gave only $1.6 \%$ benzoic acid formation while Ni supported on mixture of anatase and rutile form converted almost the same amount at same conditions. It is clear that doping oxide of nickel with $\mathrm{TiO}_{2}$, reduces significantly the photooxidation activity of undoped $\mathrm{TiO}_{2}$. Nickel oxide affect negatively the photoreactivity of $\mathrm{TiO}_{2}$ by reducing the number of active sites and the life times of the hole-electron pairs generated by band gap irradiation. Moreover the specific surface area of Ni-doped sample is higher than other samples which reduces the absorption of $\mathrm{H}_{2} \mathrm{O}$ by $\mathrm{TiO}_{2}$ surface and generation of hydroxyl radicals. ${ }^{49}$

Thus Ni-doped $\mathrm{TiO}_{2}$ is not a catalyst for the photochemical oxidation of toluene to benzoic acid even with anatase phase. The nominal conversion to benzoic acid may be due to the photocatalytic activity of $\mathrm{TiO}_{2}$.

\section{With $\mathrm{Cu}$-doped $\mathrm{TiO}_{2}$}

Using $15 \% \mathrm{Cu}$-doped $\mathrm{TiO}_{2}$ containing anatase phase of titania, toluene conversion to benzoic acid reached $49.6 \%$ for $8 \mathrm{~h}$ irradiation. Here also the photochemical oxidation of toluene is affected by rutilation. The percentage conversion dropped to $24.1 \%$ for $10 \mathrm{~h}$ irradiation, when oxide of $\mathrm{Cu}$ is supported on rutile phase. $49.8 \%$ benzoic acid was formed with anatase supported Copper for the same irradiation time. Figure 7 gives the variation in benzoic acid formation with irradiation time using different phases of $\mathrm{TiO}_{2}$ support. Here also the oxidation activity of the catalyst is decreased by the presence of rutile. The required properties of $\mathrm{TiO}_{2}$ to act as a good catalyst support decreases on rutilation. The surface area of $\mathrm{Cu}$-doped $\mathrm{TiO}_{2}$ decreased drastically on rutilation. Decrease in the catalytic activity of the system with rutilation may also be due to the changes in distribution of metal oxide on the surface of titania, which may decrease with the crystal transformation and metal titanate formation at higher temperature where rutilation occurs. These may be the reasons for the decrease in photooxidation activity. So, this reaction also is influenced by the phase changes occurring in the support material.

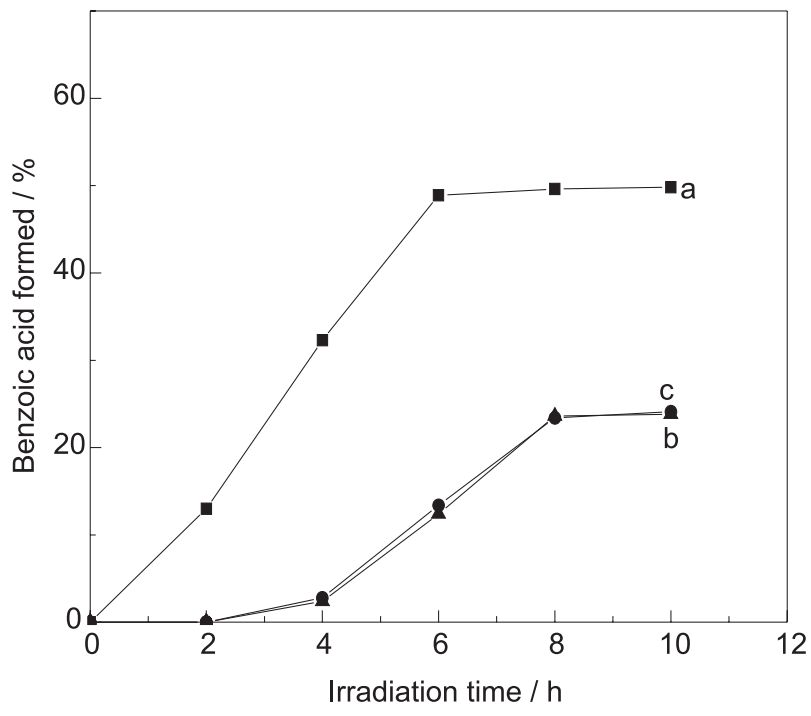

Figure 7. Variation in benzoic acid formation with different phase composition of $15 \% \mathrm{CuO} / \mathrm{TiO}_{2}$ systems. a. Containing anatase; b. Containing rutile; c. Containing both anatase and rutile.

With $\mathrm{Mn}$-doped $\mathrm{TiO}_{2}$

Figure 8 represents the variation in benzoic acid percentage with time of irradiation using oxide of $\mathrm{Mn}$ 


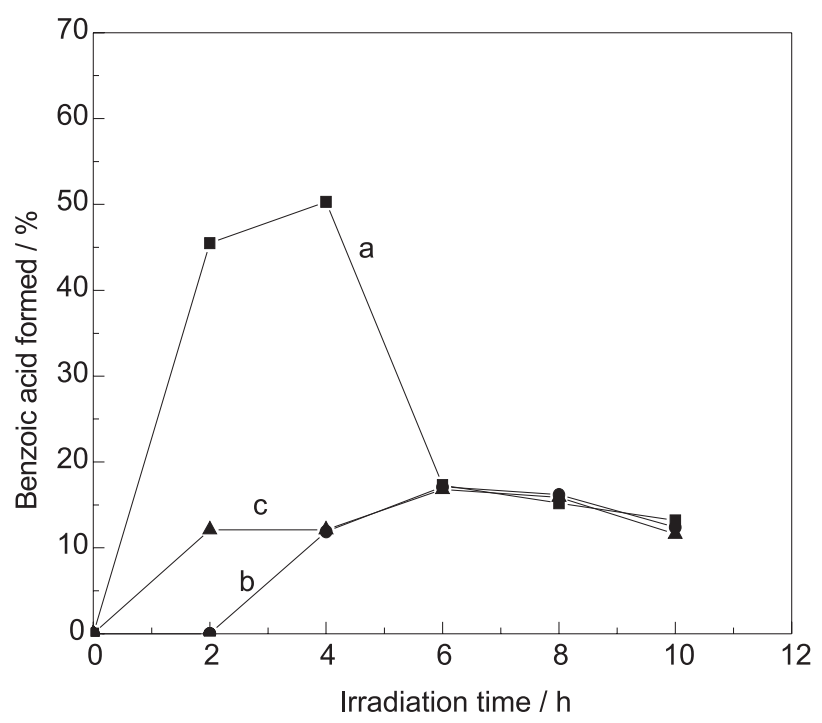

Figure 8. Variation in benzoic acid formation with different phase composition of $15 \% \mathrm{MnO}_{2} / \mathrm{TiO}_{2}$ systems. a. Containing anatase; b. Containing rutile; c. Containing both anatase and rutile.

supported on different phases of $\mathrm{TiO}_{2}$. Very interesting result is obtained for the photooxidation of toluene using Mn-doped $\mathrm{TiO}_{2}$. Here the anatase phase $\mathrm{TiO}_{2}$ supported on oxide of manganese produced $45.5 \%$ benzoic acid from toluene for $2 \mathrm{~h}$ irradiation. At $4 \mathrm{~h}$ irradiation, $50.3 \%$ benzoic acid was formed. On further increase of irradiation, the percentage of benzoic acid dropped slowly reaching $13.2 \%$ at $10 \mathrm{~h}$. This may be due to decomposition of benzoic acid to carbon dioxide and water.

As in the case of other systems, here also, rutilation lowered the oxidation activity as expected but the extent of lowering is higher as compared to others. Thus the photo oxidation of toluene is affected by the phase modification in the $\mathrm{TiO}_{2}$ support. The surface area of samples decreases drastically with rutilation, which may reflect in lowering the properties than anatase, which may be one of the reasons for lower reaction rate.

In the case of Mn-doped $\mathrm{TiO}_{2}$, prolonged irradiation resulted in the degradation since toluene layer disappeared showing the conversion of toluene but benzoic acid quantity decreased, which shows that benzoic acid is getting decomposed. The optimum time of irradiation is found to be $4 \mathrm{~h}$ where around $50 \%$ benzoic acid conversion is obtained. Thus it is clear that the Mn-doped $\mathrm{TiO}_{2}$ can act as a catalyst for the decomposition of benzoic acid and it may decompose organic pollutants.

Carbon balances were determined by measuring the amounts of consumed carbon in reactant and was recovered as carbon in $\mathrm{C}_{6} \mathrm{H}_{5}-\mathrm{COOH}$. Benzoic acid formed has carbon recovery value of $c a .99 .5 \%$, which confirms that there is no carbon deposition. After irradiation, the concentration of $\mathrm{TiO}_{2}$ remains the same and no intermediate by products were detected. A yellowish discolouration of $\mathrm{TiO}_{2}$ during photocatalytic treatment was observed due to the formation of polymeric species as reported in the literature. ${ }^{50}$ Titania particles were separated by filtration and benzoic acid is crystallized from the filtrate after concentration.

Reaction conducted in liquid phase photooxidation of toluene using the transition metal oxide doped $\mathrm{TiO}_{2}$ shows that the oxidation activity of the catalyst is sensitive to the phase modification. Higher conversions for toluene photooxidation were obtained by using the anatase phase $\mathrm{TiO}_{2}$ The degradation of 4-nitrophenol using transition metal ions impregnated on $\mathrm{TiO}_{2}$ has improved activity than bare $\mathrm{TiO}_{2}$ as reported by Di Paola et al. ${ }^{49}$ Severe decrease in photooxidation activity was observed with rutilation. Order of photooxidation activity for toluene is anatase $>$ rutile $>$ mixture of anatase and rutile.

Table 3 represents the variation in benzoic acid formation on irradiation for $6 \mathrm{~h}$ with phase composition of doped $\mathrm{TiO}_{2}$. Different metal oxide doped $\mathrm{TiO}_{2}$ exhibit different conversions for toluene photooxidation. Oxides of $\mathrm{Fe}$ and $\mathrm{Cr}$ supported on $\mathrm{TiO}_{2}$ produced more yield of benzoic acid from toluene during irradiation. The yield of benzoic acid is less with $\mathrm{Cu}$-doped $\mathrm{TiO}_{2}$. Mn-doped $\mathrm{TiO}_{2}$ is acting as a catalyst for the decomposition of the formed benzoic acid at higher irradiation time. Nickel Oxide supported on $\mathrm{TiO}_{2}$ is not a catalyst for photooxidation of toluene. The photocatalytic activity decreases in the order Cr-doped $\mathrm{TiO}_{2}>$ Fe-doped $\mathrm{TiO}_{2}>\mathrm{Cu}$-doped $\mathrm{TiO}_{2}>$ undoped $\mathrm{TiO}_{2}>$ Mn-doped $\mathrm{TiO}_{2}>$ Ni-doped $\mathrm{TiO}_{2}$.

Table 3. Variation in benzoic acid formation on irradiation for $6 \mathrm{~h}$ with phase composition of doped $\mathrm{TiO}_{2}$

\begin{tabular}{lccc}
\hline Sample & \multicolumn{3}{c}{ Benzoic acid formed $/(\%)$} \\
\cline { 2 - 4 } & With anatase & With rutile & $\begin{array}{c}\text { With anatase and } \\
\text { rutile mixture }\end{array}$ \\
\hline $\mathrm{Fe}_{2} \mathrm{O}_{3} / \mathrm{TiO}_{2}$ & 53.4 & 18.6 & 16.3 \\
$\mathrm{Cr}_{2} \mathrm{O}_{3} / \mathrm{TiO}_{2}$ & 63.6 & 17.8 & 22.0 \\
$\mathrm{NiO} / \mathrm{TiO}_{2}$ & 4.8 & 0 & 0 \\
$\mathrm{CuO} / \mathrm{TiO}_{2}$ & 48.9 & 13.4 & 12.4 \\
$\mathrm{MnO}_{2} / \mathrm{TiO}_{2}$ & 17.3 & 17.1 & 16.8 \\
\hline
\end{tabular}

\section{Mechanism of photochemical oxidation of toluene}

The mechanism of toluene degradation during irradiation is believed to be as follows. The photocatalytic reaction starts with the exposure of aqueous suspension of toluene in presence of metal oxide supported on $\mathrm{TiO}_{2}$ to UV light. After exposure to light two reaction starters are generated; one is electron $\left(\mathrm{e}^{-}\right)$and the other is positive 
electron holes $\left(\mathrm{h}^{+}\right)$. One of the notable characteristics of $\mathrm{TiO}_{2}$ is that the oxidizing power of the holes is greater than the reducing power of the excited electrons. Now $\mathrm{TiO}_{2}$ absorbs $\mathrm{H}_{2} \mathrm{O}$ on to its surface and generates hydroxyl radicals, which have strong oxidation capacity. In this reaction $\mathrm{TiO}_{2}$ is regenerated to original form as follows: $\mathrm{TiO}_{2}\left(\mathrm{~h}^{+}\right)+\mathrm{H}_{2} \mathrm{O} \rightarrow \cdot \mathrm{OH}+\mathrm{H}^{+}+\mathrm{TiO}_{2}$.

The hydroxyl radical can abstract the hydrogen from the methyl group leading to a benzyl radical.

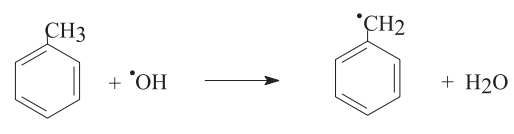

Toluene Benzyl radical

The benzyl radical can then react with $\mathrm{O}_{2}$ to form a benzylperoxy radical.

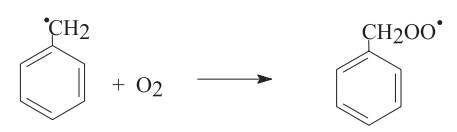

Benzyl radical

Benzylperoxy radical

The benzyl peroxy radical can couple to form a tetroxide

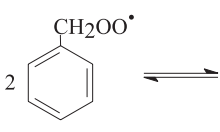

Benzyl peroxy radical

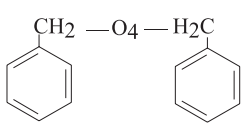

Tetroxide
The tetroxide decomposes to benzaldehyde, benzyl alcohol and molecular oxygen.

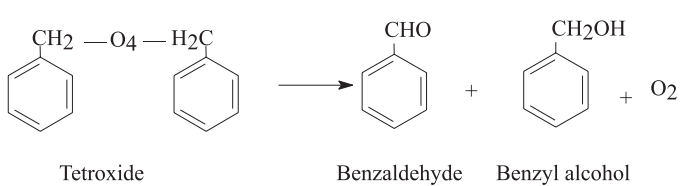

The benzyl peroxy radical can also react with a hydroperoxy radical (formed in the reaction system) to form a monoalkyl tetroxide that decomposes to benzaldehyde, molecular oxygen and water.

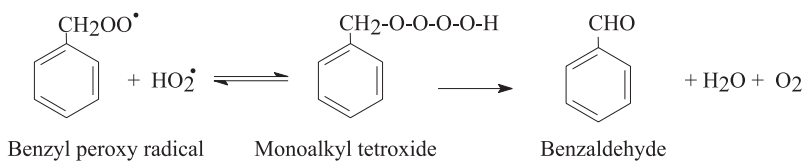

Benzaldehyde is easily oxidized into benzoic acid, especially in the presence of $\mathrm{O}_{2}$ and UV irradiation.

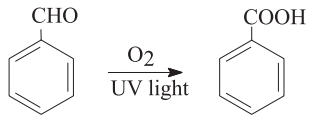

The difference in photocatalytic activity between $\mathrm{TiO}_{2}$ and doped $\mathrm{TiO}_{2}$ can be attributed to the characteristics such as the higher particle size or the lower anatase/rutile ratio of doped $\mathrm{TiO}_{2}$. Powders with more rutile could be less active due to the dehydroxylation caused by the anatase to rutile phase transformation since hydroxylation reduces hole trapping by surface hydroxyls, enhancing recombination and oxygen or organic species adsorption. A decrease in specific surface area can also affect the photo activity.

Dopants can affect the photoactivity of $\mathrm{TiO}_{2}$ by changing the number of active sites, surface groups and the acid-base properties. The different behavior of the various samples is also related to the solubility of the transition metal oxide in the $\mathrm{TiO}_{2}$ support, which depends strongly on the radius and the charge of the corresponding ion. The present study confirms that metal oxide dispersed $\mathrm{TiO}_{2}$ is better catalyst than pure $\mathrm{TiO}_{2}$. The reasons for the enhanced activity and efficiency may be due to various factors like change in the number of active sites, surface groups, acid base properties and solubility of metal oxide in $\mathrm{TiO}_{2}$.

\section{Conclusions}

Reaction conducted in liquid phase photooxidation of toluene using the transition metal oxide doped $\mathrm{TiO}_{2}$ shows that the oxidation activity of the catalyst is sensitive to the phase modification. Higher conversions for toluene photooxidation were obtained by using the anatase phase $\mathrm{TiO}_{2}$ Severe decrease in photooxidation activity was observed with rutilation. $\mathrm{Cr}$ and $\mathrm{Fe}$-doped $\mathrm{TiO}_{2}$ can give about $100 \%$ conversion in photo oxidation of toluene to benzoic acid as compared to undoped $\mathrm{TiO}_{2}$ and with $\mathrm{Cu}$ and $\mathrm{Mn}$-doped $\mathrm{TiO}_{2}$ the yield of benzoic acid is less. On irradiation for more time, in presence of $\mathrm{Mn}$-doped $\mathrm{TiO}_{2}$ degradation of benzoic acid formed takes place. Ni-doped $\mathrm{TiO}_{2}$ is not a catalyst for photooxidation of toluene to benzoic acid. Undoped $\mathrm{TiO}_{2}$ gives more yield of benzoic acid than Ni-doped $\mathrm{TiO}_{2}$. Titania particles were separated by filtration and benzoic acid is crystallized from the filtrate after concentration.

The difference in photocatalytic activity between $\mathrm{TiO}_{2}$ and doped $\mathrm{TiO}_{2}$ can be attributed to the characteristics such as the higher particle size or the lower anatase/rutile ratio of doped $\mathrm{TiO}_{2}$. Powders with more rutile could be less active due to the dehydroxylation caused by the anatase to rutile phase transformation since hydroxylation reduces hole trapping by surface hydroxyls, enhancing recombination and oxygen or 
organic species adsorption. Nickel oxide affects negatively the photoreactivity of $\mathrm{TiO}_{2}$ by reducing the number of active sites and the lifetimes of the hole-electron pairs generated by band gap irradiation. A decrease in specific surface area can also affect its photoactivity.

\section{Acknowledgments}

We express our sincere thanks to Director, Regional Research Laboratory (CSIR), Trivandrum for providing necessary facilities for the investigations; to Dr. Suresh Das and Mr.Robert Philip, photochemistry research unit RRL(T), for providing necessary facilities to do the photooxidation and to all the members of BSMR section, RRL, Trivandrum.

\section{References}

1. Snell, F. D.; Hilton, C. L.; Encyclopedia of Industrial Chemical Analysis, Wiley: New York, 1968.

2. Mark, H. F.; Othmer, D. F.; Overberger, C. G.; Seaborg, G. T.; Encyclopedia of Chemical Technology, $3^{\text {rd }}$ ed. , Wiley: New York, 1978.

3. Diebold, U.; Surf. Sci. Rep. 2003, 48, 53.

4. Schiavello, M.; Heterogeneous Photocatalysis, Wiley: New York, 1995.

5. Serpone, N.; Pelizzetti, E.; Photocatalysis: Fundamentals and Applications, Wiley: New York, 1989.

6. Fujishima, A.; Hashimoto, K.; Watanabe, T.; TiO 2 Photocatalysis: Fundamentals and Applications, BKC: Tokyo, 1999.

7. Ibusuki, T.; Takeuchi, K.; Atmos. Environ. 1986, 20, 1711.

8. Obee, T. N.; Brown, R. T.; Environ. Sci. Technol. 1995, 20, 1223.

9. Luo, Y.; ollis, D. F.; J. Catal. 1996, 163, 1.

10. Einaga, H.; Futamura, S.; Ibusuki, T.; Appl. Catal. B. 2002, 38, 215.

11. Augugliaro, V.; Coluccia, S.; loddo, V.; Marchese, L.; Martra, G.; Palmisano, L.; Schiavello, M.; Appl. Catal. B. 1999, 20, 15.

12. Martra, G.; Augugliaro, V.; Coluccia, S.; Garcia Lopez, E.; loddo, V.; Marchese, L.; Palmisano, L.; Schiavello, M.; Stud. Surf. Sci. Catal. 2000, 130, 665.

13. Cao, L.; Gao, Z.; Suib, S. L.; Obee, T. N.; Hay, S. O.; Freihaut, J. D.; J. Catal. 2000, 196, 253.

14. Fujihira, M.; Satoh, Y.; Osa, T.; Nature 1981, 293, 206.

15. Fujihira, M.; Satoh, Y.; Osa, T.; J. Electroanal. Chem. 1981, 126, 1053.

16. Navio, A.; Garcia Gomez, M.; Pradera Adrian, M. A.; Fuentes Mota, J.; J. Mol. Catal. 1996, 104, 329.

17. Augugliaro, V.; Loddo, V.; Marci, G.; Palmisano, L.; Sbriziolo, C.; Schiavello, M.; Turco Liveri, M. L.; Stud. Surf. Sci. Catal. 2000, 130, 1973.
18. Palmisano, L.; Augugliaro, V.; Sclafani, A.; Schiavello, M.; J. Phys. Chem. 1998, 92, 6710.

19. Palmisano, L.; Schiavello, M.; Sclafani, A.; Martin, C.; Martin, I.; Rives, V.; Catal. Lett. 1994, 24, 303.

20. Martin, C.; Martin, I.; Rives, V.; Palmisano, L.; Schiavello, M.; J. Catal. 1992, 134, 434.

21. Litter, I.; Navio, J. A.; J. Photochem. Photobiol. A: Chem. 1996, 98, 171.

22. Dachille, F.; Roy, R.; Am. Ceram. Soc. Bull. 1962, 41, 225.

23. Riyas, S.; Ahmed Yasir, V.; Mohan Das, P. N.; Bull. Mater. Sci. 2002, 25, 267.

24. Riyas, S.; Mohan Das, P. N.; Br. Ceram. Trans. 2004, 103, 23.

25. Larson, S. A.; Falconer, J. L.; Catal. Lett. 1997, 44, 57.

26. d'Hennezel, O.; Ollis, D. F.; J. Catal. 1997, 167, 118.

27. d'Hennezel, O.; PhD Thesis, North Carolina State University/ Ecole Centrale de Lyon, 1998.

28. Luo, Y.; Ollis, D. F.; J. Catal. $1996,1,163$.

29. Sauer, M. L.; Hale, M. A.; Ollis, D. F.; J. Photochem. Photobiol. A:Chem. 1995, 88, 169.

30. Ibusuki, T.; Takeuchi, K.; Atmos. Environ. 1986, 20, 1711.

31. Larson, S. A.; Falconer, J. L.; Catal. Lett. 1997, 44, 57.

32. Blanco, J.; Avila, P.; Bahamonde, A.; Alvarez, E.; Sanchez, B.; Romero, M.; Catal. Today 1996, 29, 437.

33. Atkinson, R.; Aschmann, S. M.; Int. J. Chem. Kinetics 1989, $21,355$.

34. Seuwen, R.; Warneck, P.; Comm. Eur. Communities 1994, 1, 137.

35. d'Hennezel, O.; Ollis, D. F.; Hightower, J. W.; Delgass, W. N.; Iglesia, E.; Bell, A. T.; Surf. Sci. Catal. 1996, 101, 435.

36. Jacoby, W. A.; Blake, D. M.; Fennell, J. A.; Boulter, J. E.; Vargo, L. M.; George, M. C.; Dolberg, S. K.; J. Air Waste Manag. Assoc. 1996, 46, 891.

37. Fu, X.; Zeltner, W. A.; Anderson, M. A.; Appl. Catal. 1995, B6, 209.

38. Sitkiewitz, S.; Heller, A.; New J. Chem. 1996, 20, 233.

39. Blanco, J.; Avila, P.; Bahamonde, A.; Alvarez, E.; Sanchez, B.; Romero, M.; Catal. Today 1996, 29, 437.

40. Atkinson, R.; Aschmann, S. M.; Int. J. Chem. Kinetics 1989, $21,355$.

41. Gennari, F. C.; Pasquevich, D. M.; J. Am. Ceram. Soc. 1998, 33, 1571.

42. Riyas, S.; Krishnan, G.; Mohan Das, P. N.; Ceram. Int. 2006, 32, 593.

43. Riyas, S.; Krishnan, G.; Mohan Das, P. N.; J. Ceram. Proces. Res. 2006, 7, 301.

44. Kolthoff, I. M.; Elving, P. J.; Sandell, E. B.; Treatise on Analytical Chemistry, Interscience, Wiley, 1961.

45. Jeffery, G. H.; Bassett, J.; Mendham, J.; Denney, R. C.; Textbook of Quantitative Chemical Analysis, Longman, London, 1989. 
46. Hiemenz.; Principles of Colloids and Surface Chemistry, Marcel Dekker, Inc: New York and Basel, 1986.

47. Marci, G.; Palmisano, L.; Sclafani, A.; Venezia, A. M.; Campostrini, R.; Carturan, G.; Martin, C.; Rives, V.; Solana, G.; J. Chem. Soc., Faraday Trans. 1996, 92, 819.
48. Navio, J. A.; Colon, G.; Bitter, M. I.; Bianco, G. N.; J. Mol. Catal. A:Chem. 1996, 106, 267.

49. Di Paola, A.; Marci, G.; Palmisano, L.; Schiavello, M.; Uosaki, K.; ikeda, S.; Ohtani, B.; J. Phys. Chem. B 2002, 106, 637. 50. Sitkiewitz, S.; Heller, A.; New J. Chem. 1996, 20, 233.

Received: July 1, 2007 Web Release Date: June 9, 2008 